\title{
Halogenated metal-organic framework glasses and liquids
}

\author{
Jingwei Hou, María Laura Ríos Gomez, Andraz`Krajnc, \\ Aoife McCaul, Shichun Li, Alice M. Bumstead, Adam F. Sapnik, \\ Zeyu Deng, Rijia Lin, Philip A. Chater, Dean S. Keeble, \\ David A. Keen, Dominique Appadoo, Bun Chan, Vicki Chen, \\ Gregor Mali, and Thomas D. Bennett
}

\section{Published version information}

Citation: J Hou et al. "Halogenated metal-organic framework glasses and liquids." Journal of the American Chemical Society, vol.142, no. 8 (2020): 3880-3890.

DOI: $\underline{10.1021 / \text { iacs.9b11639 }}$

This document is the unedited author's version of a Submitted Work that was subsequently accepted for publication in Journal of the American Chemical Society (C)2020 American Chemical Society after peer review. To access the final edited and published work see DOI above.

Please cite only the published version using the reference above. This is the citation assigned by the publisher at the time of issuing the AAM. Please check the publisher's website for any updates. 


\title{
Halogenated Metal-Organic Framework Glasses and Liquids
}

\author{
Jingwei Hou, ${ }^{1,2}$ María Laura Ríos Gómez, ${ }^{1,3}$ Andraž Krajnc, ${ }^{4}$ Aoife McCaul, ${ }^{1}$ Shichun Li, ${ }^{1,5}$ Alice M. \\ Bumstead, ${ }_{1}^{1}$ Adam F. Sapnik, ${ }^{1}$ Zeyu Deng, ${ }^{1}$ Rijia Lin, ${ }^{2}$ Philip A. Chater, ${ }^{6}$ Dean S. Keeble, ${ }^{6}$ David A. \\ Keen, ${ }^{7}$ Dominique Appadoo, ${ }^{8}$ Bun Chan, ${ }^{9}$ Vicki Chen, ${ }^{2}$ Gregor Mali, ${ }^{4}$ Thomas D. Bennett ${ }^{1, *}$ \\ ${ }^{1}$ Department of Materials Science and Metallurgy, University of Cambridge, 27 Charles Babbage Road, Cambridge, CB3 \\ OFS, UK. \\ ${ }^{2}$ School of Chemical Engineering, University of Queensland, St Lucia, QLD, 4072, Australia. \\ ${ }^{3}$ Institute of Materials Research (IIM-UNAM). Circuito Exterior, Ciudad Universitaria, Coyoacán, 04510, D. F., Mexico. \\ ${ }^{4}$ Department of Inorganic Chemistry and Technology, National Institute of Chemistry, 1001 Ljubljana, Slovenia. \\ ${ }^{5}$ Institute of Chemical Materials, China Academy of Engineering Physics, Mianyang 621900, P. R. China. \\ ${ }^{6}$ Diamond Light Source Ltd., Diamond House, Harwell Science \& Innovation Campus, Didcot, Oxfordshire OX11 0DE, UK. \\ ${ }^{7}$ ISIS Facility, Rutherford Appleton Laboratory, Harwell Campus, Didcot, Oxon OX11 0QX, UK. \\ ${ }^{8}$ Australian Synchrotron, 800 Blackburn Rd, Clayton, VIC, 3168 Australia. \\ ${ }^{9}$ Graduate School of Engineering, Nagasaki University, Nagasaki 852-8521, Japan.
}

KEYWORDS Metal-organic framework, Glass, Liquid, Melting, Solid-state NMR, THz/Far-IR, Dynamic Properties

\begin{abstract}
The synthesis of four novel crystalline zeolitic imidazolate framework (ZIF) structures using a mixed-ligand approach is reported. The inclusion of both imidazolate and halogenated benzimidazolate-derived linkers leads to glass-forming behavior by all four structures. Melting temperatures are observed to depend on both electronic and steric effects. Solid-state NMR and terahertz $(\mathrm{THz}) / \mathrm{Far}-\mathrm{IR}$ demonstrate the presence of a Zn-F bond for fluorinated ZIF glasses. In situ THz/Far-IR spectroscopic techniques reveal the dynamic structural properties of crystal, glass and liquid phases of the halogenated ZIFs, linking the melting behavior of ZIFs to the propensity of the $\mathrm{ZnN}_{4}$ tetrahedra to undergo thermally-induced deformation. The inclusion of halogenated ligands within MOFglasses improves their gas uptake properties.
\end{abstract}

\section{Introduction}

Current research on metal-organic frameworks (MOFs) has concentrated predominantly on the properties of ordered crystalline phases. ${ }^{1,2}$ However, there is growing recognition of the importance of the physical properties of MOFs. In particular, the role of disorder, defects and structural flexibility in installing beneficial physical behavior is now widely studied. ${ }^{3-8}$ It has in fact recently been demonstrated that crystallinity itself is not a prerequisite for many of the properties for which MOFs are well known, such as porosity, catalytic activity, and chemical and structural tunability. ${ }^{6,9-12}$ Consequently, non-crystalline or amorphous MOFs are attracting attention for applications in e.g. ion conductivity and molecular encapsulation. ${ }^{13}$

Conventional amorphization of MOFs is achieved through the application of high pressures, thermal treatment or ball milling of crystalline frameworks. ${ }^{12,13}$ Recently, the macroscale melting of several zeolitic imidazolate frameworks (ZIFs, including ZIF-4 (cag), ZIF-62 (cag) and ZIF-76 (lta)) has been reported at $c a .650-900 \mathrm{~K} \cdot{ }^{9,14-17}$ The melting proceeds on a subnanosecond timeframe via dissociation of the $\mathrm{Zn}$-Im (Im - imidazolate, $\mathrm{C}_{3} \mathrm{H}_{3} \mathrm{~N}_{2}^{-}$) bond, before reassociation of the Im with a different
$\mathrm{Zn}$ center. The energy required to break the $\mathrm{Zn}$-Im bond has been previously calculated as $c a .95 \mathrm{~kJ} / \mathrm{mol}$ at $840 \mathrm{~K}$ for ZIF-4 $\left[\mathrm{Zn}(\mathrm{Im})_{2}\right] .{ }^{9}$ The high-temperature liquid MOF exhibits a very high viscosity, which suppresses any re-crystallization of the glasses formed by melt-quenching. ${ }^{18}$ The glasses formed upon cooling possess a continuous random network structure, like that of amorphous $\mathrm{SiO}_{2}{ }^{9,13}$

Among the ZIF glasses known to date, ZIF-62 $\left[\mathrm{Zn}(\mathrm{Im})_{\mathrm{x}}(\mathrm{bIm})_{2}\right.$ x] (bIm - benzimidazolate, $\left.\mathrm{C}_{7} \mathrm{H}_{5} \mathrm{~N}_{2}^{-}\right)$is of particular interest because it has the lowest melting temperature. ${ }^{16,18}$ The glass, $\mathrm{a}_{\mathrm{g}}$ ZIF-62, exhibits reversible host-guest adsorption behavior, with gas uptakes of $20.1\left(\mathrm{CO}_{2}, 273 \mathrm{~K}\right)$ and $9.3\left(\mathrm{H}_{2}, 77 \mathrm{~K}\right) \mathrm{cm}^{3}$ STP g ${ }^{-1}$ at 1 bar. $^{19}$ The liquid MOF phase is however also of interest as it provides a platform from which materials with specific physical and mechanical properties can be designed and shaped. ${ }^{20}$ One example of such a material is the MOF crystalglass composite formed by embedding the as-synthesized phase of MIL-53(Al) (containing unreacted ligand within the pores) within a ZIF-62 glass, which results in stabilization of the hightemperature, open-pore phase of MIL-53(Al) at room temperature. $^{21,22}$ 
Currently, there are over 80,000 known MOF structures, though melting behavior has mainly been confined to the ZIF family. ${ }^{13,23}$ Various strategies have been proposed to construct new systems displaying accessible liquid states ${ }^{24}$ or, alternatively, to lower the melting point $\left(T_{\mathrm{m}}\right)$ of existing systems. Such efforts are highly valuable due to (i) the provision of a wider operational temperature window between melting and decomposition, which allows regulation of liquid viscosity, and (ii) the ability to combine a wider range of crystalline structures within the liquid state due to the lower temperatures needed for crystalglass composite processing. Our understanding of the various factors which affect melting remains however relatively poor, as does our knowledge of the structure, dynamics and chemical reactivity of the liquid MOF state.

In one of the few studies performed in the area, high-pressure high-temperature diffraction demonstrated the negative melting-curve behavior of ZIF-62. ${ }^{19}$ The structure shows a reduction in melting temperature at high pressures (up to $2 \mathrm{GPa}$ ), though related materials with accessible dense phases do not show this behavior. ${ }^{19,25}$ The melting temperature of ZIF-62 can also be regulated via alternating the Im:bIm ligand ratio in the structure. ${ }^{16,18}$

Coudert and co-workers ${ }^{26}$ have also investigated the differences in thermal response between $\mathrm{ZIF}-4$ and $\mathrm{ZIF}-8\left[\mathrm{Zn}(\mathrm{mIm})_{2}\right](\mathrm{mIm}$ - 2-methylimidazolate, $\mathrm{C}_{4} \mathrm{H}_{5} \mathrm{~N}_{2}{ }^{-}$). The experimental $T_{\mathrm{m}}$ of $\mathrm{ZIF}$ 4 is $863 \mathrm{~K}$, whilst ZIF-8 decomposes before any possible melting event. ${ }^{14,26}$ Computationally, the $T_{\mathrm{m}}$ of ZIF- 4 and ZIF- 8 were found to be between $1200-1500 \mathrm{~K}$ and above $1750 \mathrm{~K}$, respectively. This difference was ascribed to a greater energy barrier for diffusion in ZIF-8, which itself was proposed to be a result of the lack of stabilizing dispersive interactions for mIm linkers in the liquid state (due to the more porous structure of ZIF-8 compared to ZIF-4).

Here, motivated by the prospect of expanding the family of ZIF glasses, realizing new methods to regulate $T_{\mathrm{m}}$ and $T_{\mathrm{g}}$ (glass transition temperature) and developing a greater understanding of melting behavior and dynamics of the liquid ZIF state, we explore the synthesis of a series of novel glass-forming halogenated ZIF structures. The incorporation of halogenated ligands within MOFs has recently been shown to improve the stiffness of frameworks, ${ }^{27}$ whilst they are also capable of introducing permanent dipole moments and facilitating responses to electric fields. ${ }^{28}$ The electron withdrawing nature of $-\mathrm{F}$ and $-\mathrm{Cl}$ functionalized ligands also provides an avenue to regulate the melting behavior of the ZIFs, yet this has not been probed. In this work, four novel mixed ligand ZIFs are constructed using halogenated bIm-based ligands. A combined array of techniques including ${ }^{19} \mathrm{~F}$ solid-state nuclear magnetic resonance (NMR) and in situ TeraHertz/Far-Infrared (THz/Far-IR) spectroscopy are used to study the effect of halogenation upon melting behavior, and the dynamic structure of the resultant liquids. The porosity and mechanical behavior of the novel ZIF glasses formed upon melt quenching are characterized, finding improvement over their non-halogenated counterparts.

\section{Results and Discussion}

\section{Crystalline halogenated ZIF structures}

In order to produce ZIF glasses with accessible permanent porosity, we selected 5-chlorobenzimidazolate (5-ClbIm $\mathrm{C}_{7} \mathrm{H}_{4} \mathrm{~N}_{2} \mathrm{Cl}^{-}$), 5-chloro-2-methylbenzimidazolate (5-Cl-2-mbIm $-\mathrm{C}_{8} \mathrm{H}_{6} \mathrm{~N}_{2} \mathrm{Cl}^{-}$), 5-fluorobenzimidazolate (5-FbIm $-\mathrm{C}_{7} \mathrm{H}_{4} \mathrm{~N}_{2} \mathrm{~F}^{-}$),

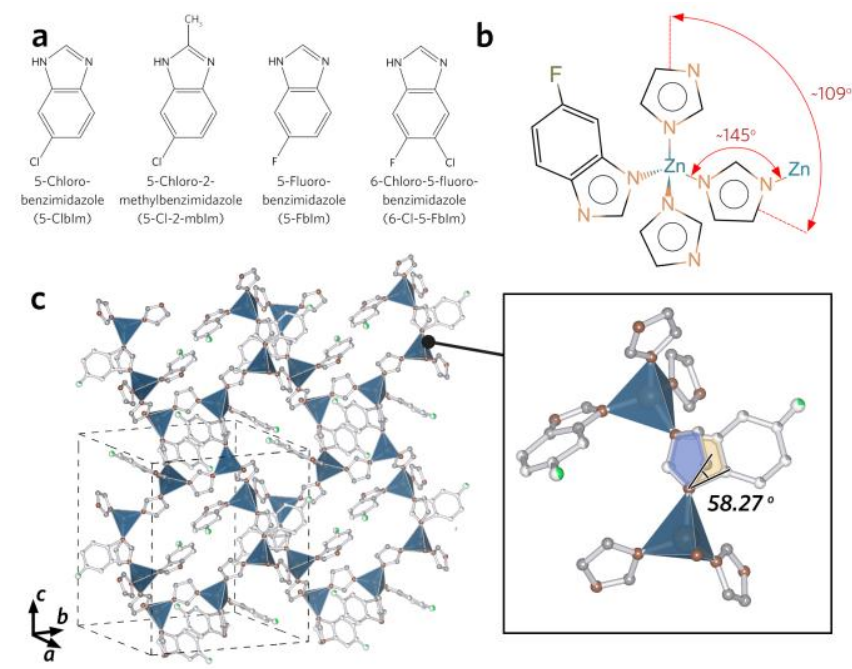

Figure 1. (a) Representations of the halogenated benzimidazolate ligands used in this study. (b) Building unit of ZIF-UC-4 (5-FbIm) with four independent linkers. (c) Representative slice of ZIF-UC-4 (5-FbIm) structure $\left(\mathrm{N}\right.$, orange; $\mathrm{C}$, grey; $\mathrm{ZnN}_{4}$ tetrahedra, blue; $\mathrm{F}$, green), showing the six- and four-membered rings. For clarity, only the range of fractional coordinates from 0.3 to 0.8 along $a$ axis is shown, hydrogen and solvent atoms are omitted. Insert highlights a $58.27^{\circ}$ orientation deviation of the 5 -FbIm linker from the corresponding Im linker position.

and 6-chloro-5-fluorobenzimidazolate (6-Cl-5-FbIm $\mathrm{C}_{7} \mathrm{H}_{3} \mathrm{~N}_{2} \mathrm{ClF}^{-}$) linkers, alongside Im (Figure 1a). This followed from a previous report of the use of Im to promote melting, and 5-ClbIm as a bulky linker to prevent the collapse of pore channels upon glass formation, allowing the diffusion of guest molecules in and out of the formed quenched glasses. ${ }^{17}$ These linkers also provided an array of halogenated functionalities, in order to study the effect on melting behavior.

Four isostructural frameworks based on the glass-forming ZIF62 structure were synthesized via a solvothermal process, adapted from that of ZIF-62 (see Supporting Information). ${ }^{17,21}$ These materials are referred to as ZIF-UC-2 (6-Cl-5-FbIm), ZIF-UC-3 (5-Cl-2mbIm), ZIF-UC-4 (5-FbIm) and ZIF-UC-5 (5-ClbIm) respectively. UC indicates the University at which these structures were synthesized. The addition of aqueous sodium hydroxide solution, as reported by others, ${ }^{29}$ was found to be beneficial for the inclusion of bIm-based linkers in ZIF-UC3-5, due to facile deprotonation in solution. ${ }^{29}$ After the removal of occluded ligands from the internal pores, single-crystal Xray diffraction was carried out on suitable crystals. All four frameworks are found to crystallize in the orthorhombic $\mathrm{Pbca}$ space group with the same 4- and 6-membered ring containing cag network topology as ZIF-62 (Figure S1-S13 and Table S1S8). ${ }^{30}$

Like the reported ZIF-62 structure, the asymmetric units of ZIFUC-2 to ZIF-UC-5 include two independent $\mathrm{Zn}$ atoms, and four organic linkers (Figure 1b). The preference for structural inclusion of the halogenated ligands, described by their total occupancy factors, follows the order 5-FbIm (ZIF-UC-4) > 5-ClbIm $($ ZIF-UC-5) $>$ 5-Cl-2-mbIm (ZIF-UC-3) $>$ 6-Cl-5-FbIm 
Table 1. Structural information from single-crystal X-ray diffraction. For solvent occupancy, for ZIF-UC-2 (6-Cl-5-FbIm) and ZIF-UC-4 (5-FbIm), the residual electronic density was too low to assign solvent molecules in the asymmetric unit. ZIF-UC-3 and ZIF-UC-4 were refined considering just DMF solvent molecules because this solvent was used in a higher amount in comparison with DEF (see refinement details in the SI).

\begin{tabular}{ccccccc}
\hline \multirow{2}{*}{ Materials } & \multicolumn{3}{c}{ Cell parameters $(\AA)$} & $\begin{array}{c}\text { Unit cell } \\
\text { volume }\left(\AA^{3}\right)\end{array}$ & $\begin{array}{c}\text { Halogenated linker } \\
\text { total occupancy }(\%)\end{array}$ & $\begin{array}{c}\text { Solvent occupany } \\
(\%)\end{array}$ \\
\cline { 2 - 4 } & $a$ & $b$ & $c$ & $4404.5(2)$ & 26 & - \\
\hline $\begin{array}{c}\text { ZIF-UC-2 (6-Cl-5- } \\
\text { FbIm) }\end{array}$ & $15.5560(5)$ & $15.6538(5)$ & $18.0875(6)$ & & 38 & $78(3)$ \\
\hline $\begin{array}{c}\text { ZIF-UC-3 (5-Cl-2- } \\
\text { mbIm) }\end{array}$ & $15.8749(6)$ & $16.2805(6)$ & $18.0681(6)$ & $4669.7(4)$ & 68 & - \\
\hline ZIF-UC-4 (5-FbIm) & $15.6970(8)$ & $15.9694(1)$ & $17.9282(2)$ & $4494.1(5)$ & 57 & $39(9)$ \\
\hline ZIF-UC-5 (5-ClbIm) & $15.7260(8)$ & $16.0184(1)$ & $18.1617(1)$ & $4575.0(5)$ & 6 \\
\hline
\end{tabular}

(ZIF-UC-2) (Table 1). This tendency is consistent with the trend expected for their steric indexes, $\delta$ (the product of the van der Waals volume of the linker and its size $),{ }^{31}$ where bulkier halogenated ligands have lower probabilities of substituting the Im linker in the framework structure. This is consistent with our previous work. ${ }^{32}$

Restrictions on ligand occupancy originate from either the symmetry operations of the specific crystallographic site, or from the steric indexes of the halogenated linkers (see Supporting Information). This leads to a distribution of the halogenated ligands in the four structures, which results in different degrees of disorder. In the first case, the corresponding sites have a maximum occupancy of $50 \%$, which prevents symmetry-related bIm-derived linkers coming into contact with each other. In the second case, the increased steric index of bIm-derived linkers relative to Im, results in a shift of the halogenated benzimidazolate linker away from the original position to avoid clashing with a neighbor Im linker in a $100 \%$ occupied position. This shift results in partial occupancy of the crystallographic sites normally occupied by solvent molecules, ${ }^{32}$ reducing the occupancy of the halogenated linker due to the competition with solvent molecules.

Therefore, systems in which the total occupancy factor of the halogenated linker is less than $50 \%$ contain just one disordered imidazolate position, and only two different configurations for the asymmetric unit (Figure 1c and Figures S1-S13), i.e. ZIFUC-2 (6-Cl-5-FbIm) and ZIF-UC-3 (5-Cl-2-mbIm) (Table 1). Structures with higher occupancies, on the other hand, possess two disordered linker positions. This is the case for ZIF-UC-4 (5-FbIm) and ZIF-UC-5 (5-ClbIm). This results in four possible configurations for the asymmetric unit, creating a higher degree of structural disorder in the system.

The bulk phase purity of the samples was further confirmed by Pawley refinement of powder X-ray diffraction data (PXRD), using lattice parameters from the determined single-crystal structures. Good agreement between the two confirms the formation of phase-pure samples of halogenated ZIFs (Figure S14). ${ }^{1} \mathrm{H}$ solution NMR spectroscopy (Figure S15-18) was carried out, by digesting samples of crystalline ZIF-UC-2 to ZIF$\mathrm{UC}-5$ in a mixture of $\mathrm{DCl} / \mathrm{D}_{2} \mathrm{O}(35 \% ; 0.1 \mathrm{~mL})$ and $\mathrm{DMSO}-\mathrm{d}_{6}$ $(0.5 \mathrm{~mL})$. The $\mathrm{NCHN}$ chemical shifts for Im ( $\sim 9 \mathrm{ppm}$ region, $\left.\mathrm{NCH} \mathrm{N}_{\mathrm{Im}}\right)$, the substituted bIm linkers $\left(\sim 9.5 \mathrm{ppm}\right.$ for $\mathrm{NCHN}_{5-}$ ClbIm, $\mathrm{NCH}_{5-\mathrm{FbIm}}, \quad \mathrm{NCH}_{6-\mathrm{Cl}-5-\mathrm{FbIm}}$ and $\sim 2.75 \mathrm{ppm}$ for

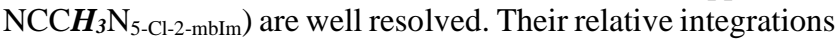
are used to determine the relative ratio of the two linkers in each mixed-linker MOF, and subsequently the chemical formula for each ZIF structure: ZIF-UC-2 [Zn(Im) ${ }_{1.84}(6-\mathrm{Cl}-5-$
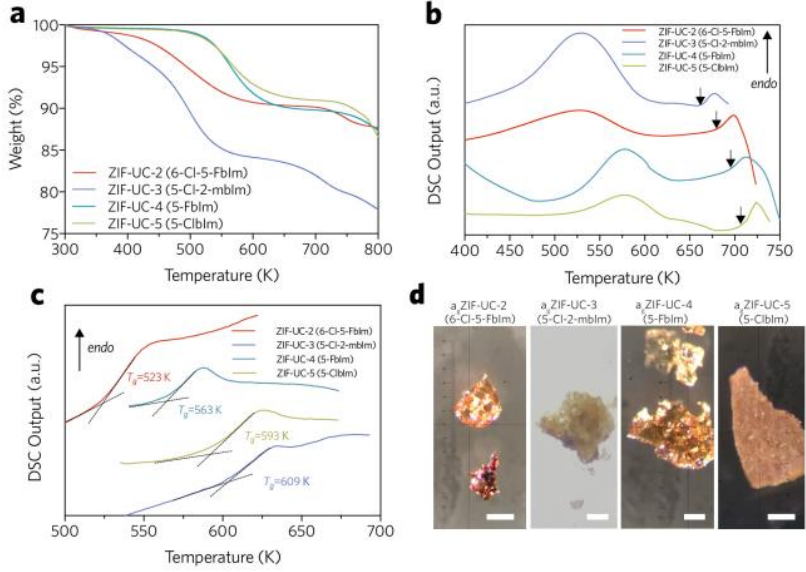

Figure 2. (a) TGA and (b) DSC profiles of the crystalline powder heating at a rate of $20 \mathrm{~K} \mathrm{~min}^{-1}$ under argon. (c) Second upscan DSC profiles of the melted-quenched glass sample at a rate of $10 \mathrm{~K} \mathrm{~min}^{-1}$. (d) Microscopic image of the melt-quenched glass samples. The scale bars are $25 \mu \mathrm{m}$.

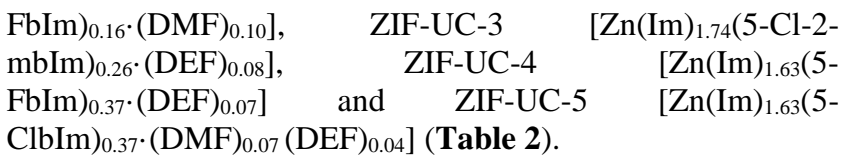
Thermal behavior and glass formation

Thermogravimetric analysis (TGA) carried out on the crystalline samples shows the removal of the remaining solvents $(N, N$ dimethylformamide and $N, N$-diethylformamide) at $c a .500 \mathrm{~K}$, followed by thermal decomposition at $c a$. $730 \mathrm{~K}$ for ZIF-UC-2 (6-Cl-5-FbIm), $720 \mathrm{~K}$ for ZIF-UC-3 (5-Cl-2-mbIm), $750 \mathrm{~K}$ for ZIF-UC-4 (5-FbIm) and ZIF-UC-5 (5-ClbIm) (Figure 2a). Initial differential scanning calorimetry (DSC) scans on the crystalline samples contains endotherms at $c a$. $530 \mathrm{~K}$ corresponding to the loss of solvent from the frameworks, followed by endotherms ascribed to melting starting at $c a .679 \mathrm{~K}$ for ZIF-UC-2 (6-Cl-5-FbIm), $663 \mathrm{~K}$ for ZIF-UC-3 (5-Cl-2-mbIm), $694 \mathrm{~K}$ for ZIF-UC-4 (5-FbIm) and $705 \mathrm{~K}$ for ZIF-UC-5 (5-ClbIm) (Figure $2 \mathrm{~b}$ and Table 2 ).

In a separate experiment, to avoid excessive thermal decomposition, crystalline samples were heated above their corresponding melting onset temperatures $(693 \mathrm{~K}$ for ZIF-UC-2 (6-Cl-5FbIm), $683 \mathrm{~K}$ for ZIF-UC-3 (5-Cl-2-mbIm), $708 \mathrm{~K}$ for ZIF-UC$4(5-\mathrm{FbIm})$ and $723 \mathrm{~K}$ for ZIF-UC-5 (5-ClbIm)), and then cooled back to room temperature. The glasses formed are termed $a_{\mathrm{g}}$ ZIF-UC-2 (6-Cl-5-FbIm), $\mathrm{a}_{\mathrm{g}}$ ZIF-UC-3 (5-Cl-2mbIm), a $a_{\mathrm{g}}$ IF-UC-4 (5-FbIm) and $\mathrm{a}_{\mathrm{g}}$ ZIF-UC-5 (5-ClbIm), with terminology in accordance with previous publications, ${ }^{32,33}$ 
Table 2. Composition and thermal behavior of halogenated ZIF crystals and their melt-quenched glasses.

\begin{tabular}{|c|c|c|c|c|c|}
\hline & $\begin{array}{c}\text { ZIF-UC-2 } \\
(6-\mathrm{Cl}-5-\mathrm{FbIm})\end{array}$ & $\begin{array}{c}\text { ZIF-UC-3 } \\
(5-\mathrm{Cl}-2-\mathrm{mbIm})\end{array}$ & $\begin{array}{c}\text { ZIF-UC-4 } \\
(5-F b I m)\end{array}$ & $\begin{array}{l}\text { ZIF-UC-5 } \\
(5-C l b I m)\end{array}$ & ZIF-62 $2^{14}$ \\
\hline $\begin{array}{l}\text { Crystal precursor } \\
\text { (Single crystal) }\end{array}$ & $\begin{array}{c}\mathrm{Zn}(\mathrm{Im})_{1.87} \\
(6-\mathrm{Cl}-5-\mathrm{Fb} \operatorname{Im})_{0.13}\end{array}$ & $\begin{array}{c}\mathrm{Zn}(\mathrm{Im})_{1.81} \\
(5-\mathrm{Cl}-2-\mathrm{mbIm})_{0.19}\end{array}$ & $\begin{array}{l}\mathrm{Zn}(\operatorname{Im})_{1.66} \\
(5-\mathrm{Fb} \operatorname{Im})_{0.34}\end{array}$ & $\begin{array}{c}\mathrm{Zn}(\operatorname{Im})_{1.72} \\
(5-\mathrm{ClbIm})_{0.28}\end{array}$ & - \\
\hline $\begin{array}{l}\text { Crystal precursor } \\
\left({ }^{1} \mathrm{H} \text { Liquid NMR) }\right.\end{array}$ & $\begin{array}{c}\mathrm{Zn}(\mathrm{Im})_{1.84} \\
(6-\mathrm{Cl}-5-\mathrm{FbIm})_{0.16} \\
\cdot(\mathrm{DMF})_{0.10}\end{array}$ & $\begin{array}{c}\mathrm{Zn}(\mathrm{Im})_{1.74} \\
(5-\mathrm{Cl}-2-\mathrm{mbIm})_{0.26} \\
\cdot(\mathrm{DEF})_{0.08}\end{array}$ & $\begin{array}{c}\mathrm{Zn}(\operatorname{Im})_{1.63} \\
(5-\mathrm{FbIm})_{0.37} \\
\cdot(\mathrm{DEF})_{0.07}\end{array}$ & $\begin{array}{c}\mathrm{Zn}(\operatorname{Im})_{1.63} \\
(5-\mathrm{ClbIm})_{0.37} \\
\cdot(\mathrm{DMF})_{0.07}(\mathrm{DEF})_{0.04}\end{array}$ & $\begin{array}{c}\mathrm{Zn}(\operatorname{Im})_{1.75} \\
(\mathrm{~b} \operatorname{Im})_{0.25}\end{array}$ \\
\hline $\begin{array}{l}\text { Melt-quenched glass } \\
\left({ }^{1} \mathrm{H} \text { Liquid NMR) }\right.\end{array}$ & $\begin{array}{c}\mathrm{Zn}(\mathrm{Im})_{1.90} \\
(6-\mathrm{Cl}-5-\mathrm{FbIm})_{0.10}\end{array}$ & $\begin{array}{c}\mathrm{Zn}(\mathrm{Im})_{1.75} \\
(5-\mathrm{Cl}-2-\mathrm{mbIm})_{0.25}\end{array}$ & $\begin{array}{c}\mathrm{Zn}(\operatorname{Im})_{1.63} \\
(5-\mathrm{FbIm})_{0.37}\end{array}$ & $\begin{array}{c}\mathrm{Zn}(\mathrm{Im})_{1.69} \\
(5-\mathrm{ClbIm})_{0.31}\end{array}$ & - \\
\hline $\begin{array}{l}\text { Melting onset temperature } \\
\quad\left(T_{\mathrm{m}} \text { for crystal }\right)\end{array}$ & $679 \mathrm{~K}$ & $663 \mathrm{~K}$ & $694 \mathrm{~K}$ & $705 \mathrm{~K}$ & $673 \mathrm{~K}$ \\
\hline $\begin{array}{c}\text { Glass transition } \\
\text { temperature ( } T_{\mathrm{g}} \text { for glass) }\end{array}$ & $523 \mathrm{~K}$ & $609 \mathrm{~K}$ & $563 \mathrm{~K}$ & $593 \mathrm{~K}$ & $591 \mathrm{~K}$ \\
\hline$T_{\mathrm{g}} / T_{\mathrm{m}}$ & 0.77 & 0.92 & 0.81 & 0.84 & 0.88 \\
\hline
\end{tabular}

and were used for subsequent ex situ studies. This was followed by a second DSC heating scan, at $10 \mathrm{~K} \mathrm{~min}^{-1}$, which identifies $T_{\mathrm{g}} \mathrm{s}$ in each case (Figure 2c and Table 2). All melt-quenched glass samples display only diffuse scattering in their PXRD patterns, whilst optical- and scanning electron microscopy confirm the formation of coherent, continuous and glassy morphologies upon melt quenching (Figure 2d, S19 and S20). The Fouriertransform infrared spectroscopy (FTIR) spectra for the crystals and corresponding melt-quenched glasses show similar features (Figure S21). Due to the relatively close nature of the melting and thermal decomposition temperatures, the melting process was still however accompanied by a small quantity of thermal decomposition for two of the crystalline samples. Specifically, ${ }^{1} \mathrm{H}$ NMR spectroscopy carried out on the glasses (Table 2) confirms a partial loss of the bIm-derived ligand component in $\mathrm{a}_{\mathrm{g}} \mathrm{ZIF}-\mathrm{UC}-2 \quad\left[\mathrm{Zn}(\mathrm{Im})_{1.90}(6-\mathrm{Cl}-5-\mathrm{FbIm})_{0.10}\right]$ and $\mathrm{a}_{\mathrm{g}} \mathrm{ZIF}-\mathrm{UC}-5$ $\left[\mathrm{Zn}(\mathrm{Im})_{1.69}(5-\mathrm{ClbIm})_{0.31}\right]$. However, $\mathrm{a}_{\mathrm{g}} \mathrm{ZIF}-\mathrm{UC}-3\left[\mathrm{Zn}(\mathrm{Im})_{1.74}(5-\right.$ Cl-2-mbIm $\left.)_{0.26}\right]$ and $\mathrm{a}_{\mathrm{g}} \mathrm{ZIF}-\mathrm{UC}-4\left[\mathrm{Zn}(\mathrm{Im})_{1.63}(5 \text {-FbIm) })_{0.37}\right]$ are relatively unchanged compared with their crystalline precursors (Figure S22-25).

The glass transition indicates the transition from solid to liquidlike behavior upon heating. Glasses with similar organic ligand content possess transition temperatures correlated with the van der Waals radius of the added side-functional group(s); i.e.

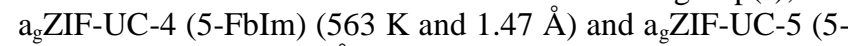
ClbIm) ( $593 \mathrm{~K}$ and $1.75 \AA$ ). This has also been found previously and is related to larger functional groups increasing the extent of non-covalent interactions within glass, or liquid structures. ${ }^{14,35}$ A lower than expected $T_{\mathrm{g}}$ for $\mathrm{a}_{\mathrm{g}} \mathrm{ZIF}-\mathrm{UC}-2$ (6-Cl-5FbIm) was observed at $523 \mathrm{~K}$, which was ascribed to the low bIm-derived linker content in the glass phase.

Trends in melting point are less clear. The onset of melting of the structures in this study, including ZIF-62 itself, are separated by $50 \mathrm{~K}$. The $19 \mathrm{~K}$ difference between ZIF-UC-4 (5-FbIm) $\left(T_{\mathrm{m}}=694 \mathrm{~K}\right)$ and ZIF-UC-5 $(5-\mathrm{ClbIm})\left(T_{\mathrm{m}}=705 \mathrm{~K}\right)$ is consistent with the greater inductive withdrawal effect of $-\mathrm{F}$ compared with - $\mathrm{Cl}$. This experimental observation was further confirmed by density functional theory (DFT) calculations carried out (Figure S26-27), which demonstrates an average difference of $2.88 \mathrm{~kJ} / \mathrm{mol}$ difference in $\mathrm{Zn}-\mathrm{N}$ bond energy between $\mathrm{Zn}(\mathrm{Im})_{3}(5-\mathrm{FbIm})$ and $\mathrm{Zn}(\mathrm{Im})_{3}(5-\mathrm{ClbIm})$ tetrahedra.
ZIF-UC-3 (5-Cl-2-mbIm) possesses the lowest $T_{\mathrm{m}}$ observed $(663 \mathrm{~K})$, i.e. lower than that of ZIF-62 $\left(T_{\mathrm{m}}=673 \mathrm{~K}\right) \cdot{ }^{14,17}$ The activation free energy, $\Delta F \$$, for melting has previously been demonstrated to follow the van't Hoff law, $\Delta F^{\ddagger}(\mathrm{T})=\Delta U^{\ddagger}-T$ $\Delta S^{\ddagger}$, where $\Delta U^{\star}$ and $\Delta S^{\star}$ are activation energy and entropy, respectively. ${ }^{9}$ From a thermodynamic point of view, the melting occurs through an activation process leading to bond breakage at the point of metastable phase of the ZIF crystal precursor, rather than at the limit of stability of the liquid phase. ${ }^{36}$ The ZIFUC-3 (5-Cl-2-mbIm) structure contains the most sterically large ligand, and thus the crystal structure formed is the most dense out of the four materials studied here. For dense ZIFs such as this one, it follows that greater dispersive interactions between the framework and the partially dissociated ligand will reduce the energy barrier to melting. For highly porous frameworks on the other hand, low level of dispersive interactions between framework and detached ligands generate a high activation free energy barrier for melting. ${ }^{26}$

\section{Glass structure}

The atomic structures of the crystalline ZIFs and their corresponding melt-quenched glasses were probed via synchrotron $\mathrm{X}$-ray total scattering. The lack of crystallinity in the glasses is confirmed by the absence of sharp features in their structure factors (Figure S28-31). Pair distribution functions (PDFs) for ZIF-UC-4 (5-FbIm) and $\mathrm{a}_{\mathrm{g}} \mathrm{ZIF}-\mathrm{UC}-4$ (5-FbIm) (Figure 3) were obtained from the total scattering data via appropriate corrections and subsequent Fourier transform (see Supporting Information). As expected, the crystalline samples contain longrange oscillations in the $D(\mathrm{r})$ on length scales above $7 \AA$, while the glass samples are relatively featureless in this region. For example, the peak in the $D(\mathrm{r})$ for crystalline ZIF-62-5-FbIm at $11.4 \AA$, marked with an ' $a$ ', is associated with the distance between the $\mathrm{Zn}$ metal center and the $\mathrm{F}$ atom on the next nearest bIm ligand. This feature is absent in the glass phase, consistent with $\mathrm{Zn}-\mathrm{N}$ bond breakage and rearrangement upon melting. Generally, below $7 \AA$, the PDF traces are similar for crystal and glass. ${ }^{18}$

Peak assignment was carried out using the PDFGUI software, ${ }^{37}$ which was used to calculate partial PDFs for the consistent atom 


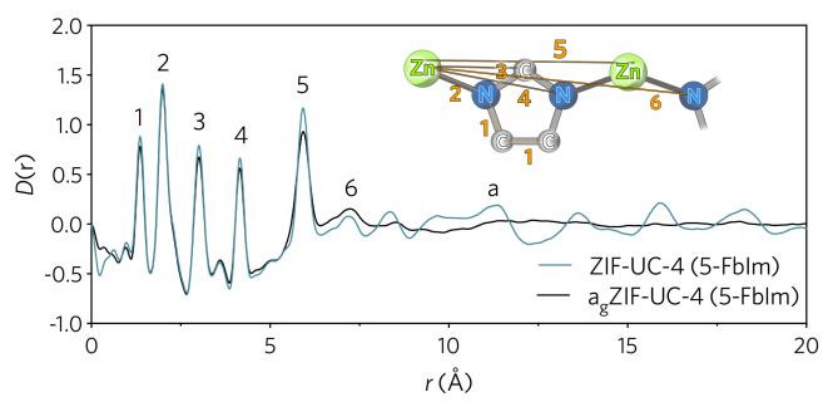

Figure 3. $D(\mathrm{r})$ for ZIF-UC-4 (5-FbIm) and agZIF-UC-4 (5-FbIm) samples. Insert highlights the peak assignment in the structures.

pairs in each system. For ZIF-UC-4 (5-FbIm), the first feature at $1.3 \AA$ is assigned to $\mathrm{C}-\mathrm{C}$ or $\mathrm{C}-\mathrm{N}$, and the intense peak at $2 \AA$ to the $\mathrm{Zn}-\mathrm{N}$ distance, which confirms $\mathrm{Zn}-\mathrm{N}$ association in the glass. Correlations between $\mathrm{Zn}$, and the second and third nearest $\mathrm{N}$ atoms of Im ligands, can be identified from the PDFs at 5.9 and $7.3 \AA$ (labelled 4 and 6 in Figure 3). These features are relatively unchanged after vitrification suggesting the preservation of this short-range order in the glass (Figure 3). Similar PDF results are also obtained for ZIF-UC-2 (6-Cl-5-FbIm), ZIF-UC-3 (5-Cl-2-mbIm) and ZIF-UC-5 (5-ClbIm) (Figure S32-34).

Figure 4 shows the ${ }^{13} \mathrm{C}$ and ${ }^{19} \mathrm{~F}$ magic angle spinning (MAS) NMR spectra of ZIF-UC-4 (5-FbIm) and $\mathrm{a}_{\mathrm{g}}$ ZIF-UC-4 (5-FbIm). In the ${ }^{13} \mathrm{C}$ MAS NMR spectrum of the crystalline material, the signals of all carbon site bIm-derived and Im ligands are clearly resolved. Assignments were performed using chemical shift prediction (ACD/I-lab NMR predictor), ${ }^{1} \mathrm{H}-{ }^{13} \mathrm{C}$ Lee-Goldburg cross polarization magic angle spinning (LG-CPMAS) and ${ }^{19} \mathrm{~F}-$ ${ }^{13} \mathrm{C}$ CPMAS measurements (Figure S35). The ${ }^{19} \mathrm{~F}$ MAS NMR spectrum of the crystalline sample contains one main peak at ca. $-115 \mathrm{ppm}$, which is composed of at least two contributions (Fig. 4b). This is explained by the relatively low 5-FbIm/Im ratio present in the material, meaning that two types of $\mathrm{Zn}$ center exist: those which are coordinated to one 5-FbIm and three Im ligands, and those which are surrounded by four Im ligands. Hence, there are pores in the material into which two 5-FbIm ligands protrude (the positions of which were related by symmetry, Figure 1c), and pores into which only one 5-FbIm ligand protrudes. The resulting local environments of 5-FbIm appear sufficiently different to give rise to resolved ${ }^{19} \mathrm{~F}$ NMR signals.

The ${ }^{13} \mathrm{C}$ MAS NMR spectrum of $\mathrm{a}_{\mathrm{g}} \mathrm{ZIF}-\mathrm{UC}-4$ (5-FbIm) exhibits broader signals at roughly the same isotropic chemical shifts as the spectrum of ZIF-UC-4 (5-FbIm). Broadening of the signals is an expected effect of increased structural disorder and the loss of crystallinity. The ${ }^{19} \mathrm{~F}$ MAS NMR spectrum of $\mathrm{a}_{\mathrm{g}} \mathrm{ZIF}-\mathrm{UC}-4$ (5-FbIm) is however more informative. In addition to the signals at about -115 ppm (which are again slightly broader than the corresponding signals in the crystalline sample), several new, broad signals appear between $-170 \mathrm{ppm}$ and $-240 \mathrm{ppm}$. NMR measurements show that F nuclei contributing to the narrow signals and F nuclei contributing to the broad signals share the same particles (Figure 4b, Figure S36).

We therefore ascribe the remarkable change in the chemical shift to a considerable change in the nature of the immediate bonding environment of $\mathrm{F}$ upon glass formation. ${ }^{19} \mathrm{~F}-{ }^{13} \mathrm{C}$ CPMAS NMR measurements confirm this (Figure S37). Selec-
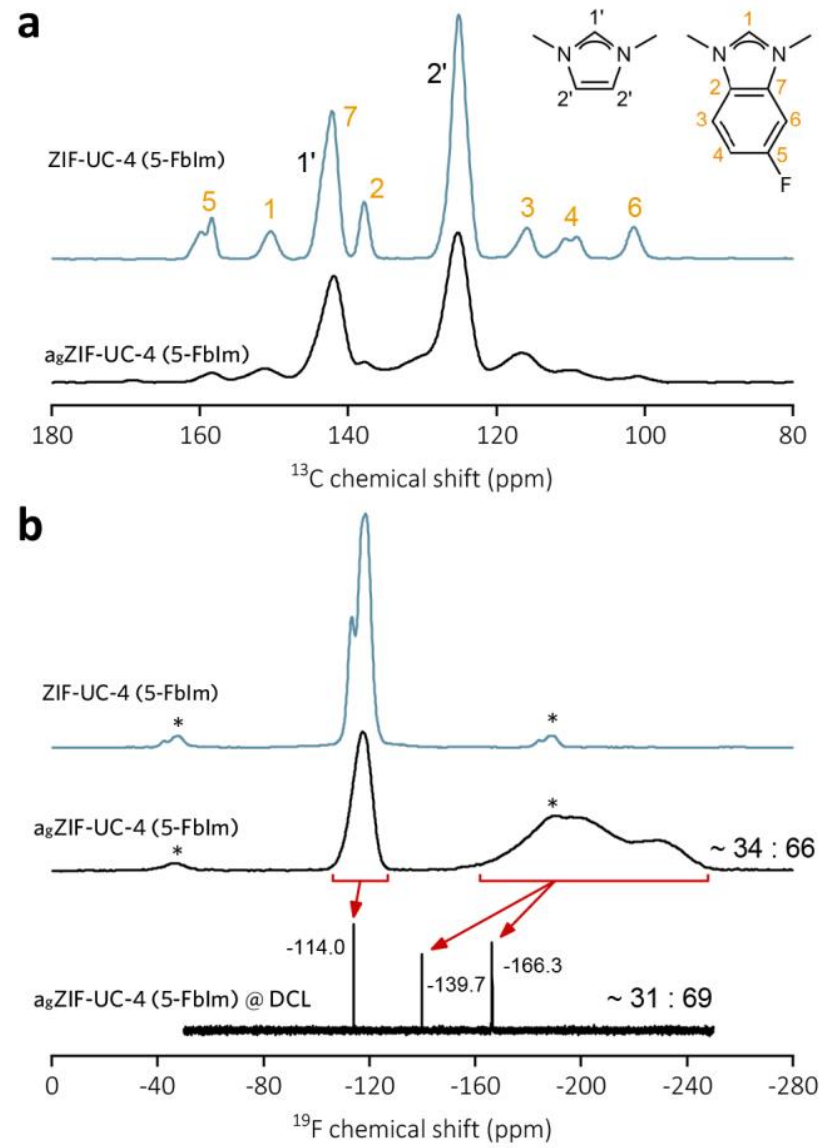

Figure 4. ${ }^{13} \mathrm{C}$ (a) and ${ }^{19} \mathrm{~F}$ (b) MAS NMR spectra of ZIF-UC-4 (5-FbIm) and $\mathrm{a}_{\mathrm{g}}$ ZIF-UC-4 (5-FbIm). The spectrum at the bottom of (b) is the ${ }^{19} \mathrm{~F}$ solution NMR spectrum of ag ZIF-UC-4 (5-FbIm), digested in DCl/DMSO-d $\mathrm{d}_{6}$. Approximate intensity ratios for the signals at about $-114.0 \mathrm{ppm}$ and all the other signals in the ${ }^{19} \mathrm{~F}$ spectra of the glass and digested glass are presented. Arrows denote correlations between the ${ }^{19} \mathrm{~F}$ NMR signals of the solid glass and digested glass. Asterisks mark positions of the spinning sidebands.

tive cross-polarization from ${ }^{19} \mathrm{~F}$ nuclei, contributing to the narrow ${ }^{19} \mathrm{~F}$ signal of the glass, clearly enhances the signal of $\mathrm{C} 5 \mathrm{C}$ nuclei, i.e. of the nuclei belonging to $\mathrm{C}$ atoms within benzyl ring, which are directly bonded to F. On the contrary, selective crosspolarization from ${ }^{19} \mathrm{~F}$ nuclei, contributing to the broad ${ }^{19} \mathrm{~F}$ signal of the glass, gives rise to a $\mathrm{C}$ spectrum in which only the two signals of Im can be detected. Surprisingly, this observation suggests that the $\mathrm{F}$ that contributes to the broad, shifted signal, is in fact not directly attached to a bIm ligand.

To further verify this observation, the ${ }^{19} \mathrm{~F}$ NMR spectrum of a digested sample of a ZIF-UC-4 (5-FbIm) is measured (Figure 4b). The spectrum shows that only a fraction of $F$ nuclei resonate at $-114 \mathrm{ppm}$, i.e. at the chemical shift typical for $\mathrm{F}$ of the dissolved 5-FbIm. The spectrum contains also a weak signal at $-139.7 \mathrm{ppm}$ and a far stronger signal at $-166.3 \mathrm{ppm}$, which can be consistent with $\mathrm{F}$ atoms attached to heavy atoms. Based on these observations, we suggest the formation of $\mathrm{Zn}-\mathrm{F}$ bonds during melting and vitrification. This would explain the observed shift of about $-200 \mathrm{ppm}$ in the solid-state ${ }^{19} \mathrm{~F}$ MAS NMR spectrum of $\mathrm{a}_{\mathrm{g}} \mathrm{ZIF}-\mathrm{UC}-4$ (5-FbIm), which agrees well with the ${ }^{19} \mathrm{~F}$ shift in $\mathrm{ZnF}_{2} \cdot{ }^{38}$ Other sources of the shifted signal are investigated, and ruled out, including the presence of paramagnetic 
species (through ${ }^{19} \mathrm{~F}$ relaxation measurements), and the presence of halogen bonds (through DFT-based calculations of the expected ${ }^{19} \mathrm{~F}$ chemical shifts) (Figures $\mathbf{S 3 8}$ and S39). Very similar observations are found also for ag ZIF-UC-2 (6-Cl-5-FbIm) (Figure S40). We suspect that the mechanism of dissociation may be similar to thermally activated radical processes in e.g. halogenated benzene compounds (e.g. chlorobenzene) ${ }^{39} \mathrm{We}$ might also suggest that the fate of the molecule after defluorination, is to perhaps form a benzyne intermediate, allowing further reaction with imidazole to form heterocyclic structures or, alternatively, to form $N$-Alkyl- $N$ '-arylimidazolium salts. This is however far beyond the scope of this work and investigations would be necessary. ${ }^{40-42}$

\section{THz/Far-IR study of bonding environments}

While the mid-range IR region is usually associated with fundamental molecular vibrations, THz/Far-IR spectra can reveal spectral features associated with quasi-localized and collective framework dynamic properties, which provides an effective probe to study dynamic framework properties upon glass formation. ${ }^{43}$ Synchrotron THz/Far-IR absorption spectroscopy has been shown to be useful in determining the spectra of dynamic vibrational motions up to $\sim 700 \mathrm{~cm}^{-1}, \sim 21 \mathrm{THz}$. The spectra above this region are not shown due to the cut-off by the beam splitter used for this beamline instrument.

Compared to the ZIF precursors $\left(\mathrm{Zn}\left(\mathrm{NO}_{3}\right)_{2}\right.$, HIm and 5-F-1HbIm, Figure S41), there are three main sources of low-energy vibrations of crystalline ZIF-UC-4 (5-FbIm) within the spectral region below $700 \mathrm{~cm}^{-1}$ (Figure 5); in-plane and out-of-plane aromatic ring deformations ( $c a .630-700 \mathrm{~cm}^{-1}$ ), $\mathrm{Zn}-\mathrm{N}$ stretching movements (ca. 280-330 $\mathrm{cm}^{-1}$ ) and 4-membered and 6-membered ring collective motions $\left(c a .30-200 \mathrm{~cm}^{-1}\right){ }^{44}$ The experimental spectrum shows similarities with the theoretical DFT calculations on the $\mathrm{Zn}(\mathrm{Im})_{3}(5-\mathrm{FbIm})$ tetrahedron $\left(150-700 \mathrm{~cm}^{-}\right.$ ${ }^{1}$, Figure S42). It should be emphasized that for the low-wavenumber region it is difficult to establish a good agreement between experimental and calculated data due to the complexity of the collective framework vibrations $\left(23-100 \mathrm{~cm}^{-1}\right.$, Figure S43). ${ }^{45}$

For the melt-quenched glass phase, a clear peak broadening compared with the crystal precursor is observed, especially in the region of 23-200 $\mathrm{cm}^{-1}$ (Figure 5), which has been linked to the collective movement of gate-opening and breathing effects involving 4- and 6-membered rings. ${ }^{44}$ Similar behavior is also observed for crystalline and glass ZIF-UC-2 (6-Cl-5-FbIm) (Figure S44-45), ZIF-UC-3 (5-Cl-2-mbIm) (Figure S46-47), ZIF-UC-5 (5-ClbIm) (Figure S48-49) and ZIF-62 (Figure S5051). In addition, the presence of a broad peak centered at $c a$. $440 \mathrm{~cm}^{-1}$, as suggested by the 2 nd derivative spectra in the insert, is consistent with the emergence of a $\mathrm{Zn}-\mathrm{F}$ bond after vitrification. ${ }^{46}$ DFT calculations on a $\mathrm{Zn}(\mathrm{Im})_{3}(\mathrm{~F})$ tetrahedron confirm this, with good agreement in peak position $\left(c a .420 \mathrm{~cm}^{-1}\right.$, Figure S52). The emergence of a broad peak ( ca. $\left.460 \mathrm{~cm}^{-1}\right)$ assigned to $\mathrm{Zn}-\mathrm{F}$ is also observed for ZIF-UC-2 (6-Cl-5-FbIm) after vitrification (Figure S44), whilst this broad peak is (evidently) absent for the ZIFs which do not contain the fluoro moiety - ZIF-UC-3 (5-Cl-2-mbIm), ZIF-UC-5 (5-ClbIm) and ZIF62 (Figure S46, 48 and 50).

Dynamic properties of crystal, glass and liquid
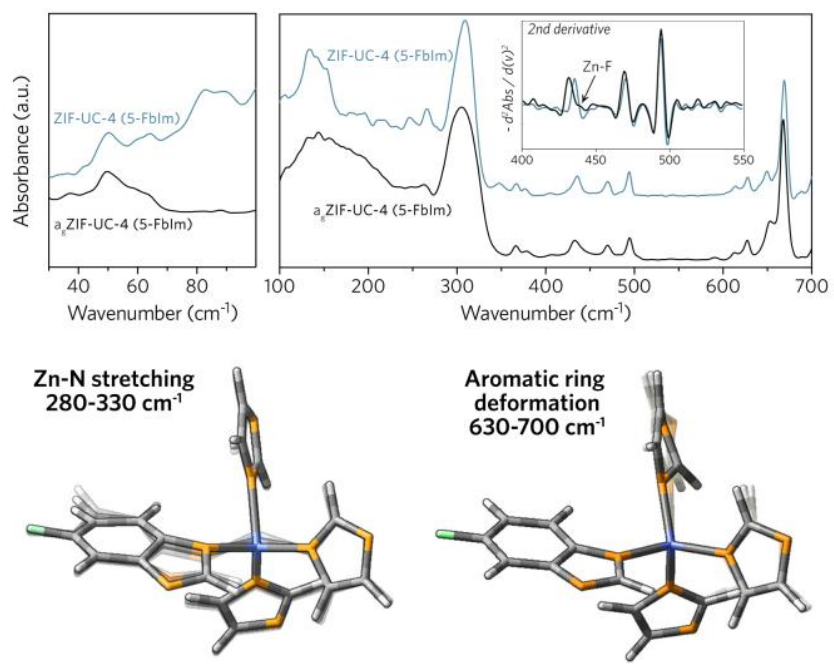

Figure 5. THz/Far-IR spectra of ZIF-UC-4 (5-FbIm) and $\mathrm{a}_{\mathrm{g}} \mathrm{ZIF-UC-4}$ (5$\mathrm{FbIm}$ ) with the insert being the 2nd derivative of the spectra highlighting the emergence of a shoulder peak at around $440 \mathrm{~cm}^{-1}$ after melt quenching, and the schematic diagram of deformation modes of $\mathrm{ZnIm}_{3} 5$-FbIm tetrahedra and aromatic rings used for DFT calculations. Zn: blue; N: orange; F: green; C: grey; H: white.

The relatively low glass transition temperature of the halogenated ZIF glasses opens opportunities to probe vibrational properties and low-frequency conformational dynamics in the liquid and glass phases, and compare these to those present in the crystalline solids. In situ heating experiments up to $573 \mathrm{~K}$ were performed at the Australian Synchrotron THz/Far-IR beamline. An in-house built gas purge-box was used to maintain an argon environment during the heating process (Figure S53). Due to the absence of thermal hysteresis for the THz/Far-IR spectra during heating and subsequent cooling steps (Figure S54), only the heating cycle was investigated.

Heating of ZIF-UC-4 (5-FbIm) and $\mathrm{a}_{\mathrm{g}} \mathrm{ZIF}-\mathrm{UC}-4$ (5-FbIm) to $573 \mathrm{~K}$ do not lead to a significant change in peak shape, with only a redshift in the peak positions for $\mathrm{Zn}-\mathrm{N}$ tetrahedra observed (ca. 310-300 $\mathrm{cm}^{-1}$ and 305-290 $\mathrm{cm}^{-1}$, Figure 6a-b and Figure S55). Ryder et al. previously demonstrated that the the quasi-delocalized $\mathrm{ZnN}_{4}$ vibrational modes obey the Bose-Einstein distribution: ${ }^{47,48}$

$$
v(T)=v_{0}-\frac{X_{R} T_{C}}{\exp \left(\frac{T_{C}}{T}\right)-1} \text { where } \quad T_{c}=\frac{h v_{0}}{k_{B}}
$$

where $v_{0}$ is the frequency of the vibration at $0 \mathrm{~K}, T_{\mathrm{c}}$ is the vibrational temperature $(\mathrm{K})$, which is obtained from statistical thermodynamics via the Planck constant, $h$, and the Boltzmann constant, $k_{\mathrm{B}}$. In particular, they defined the linear curve fitting slope, $X_{\mathrm{R}}$ as the spectral position shift coefficient. $X_{\mathrm{R}}$ was demonstrated to be correlated to the thermally-induced deformation of the $\mathrm{ZnN}_{4}$ environment, and thus affected by the exact nature of the coordinative environment. Whilst a detailed quantum mechanical analysis of this Bosonic behaviour lies beyond the scope of this paper, we applied the same logic here to deduce values of $X_{\mathrm{R}}$ for all crystalline and glass phases.

Compared with the crystal precursor, a clear increase of the $X_{\mathrm{R}}$ value of $\mathrm{Zn}-\mathrm{N}$ stretching for the glass phase is observed (Figure 6c). This is followed by a more significant enhancement above the $T_{\mathrm{g}}(563 \mathrm{~K})$ for the liquid phase, which demonstrates the greater flexibility of the $\mathrm{Zn}$ environment in the liquid phase. 


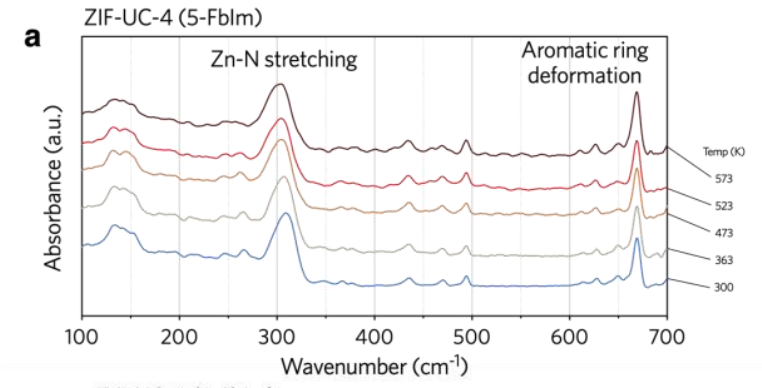

b
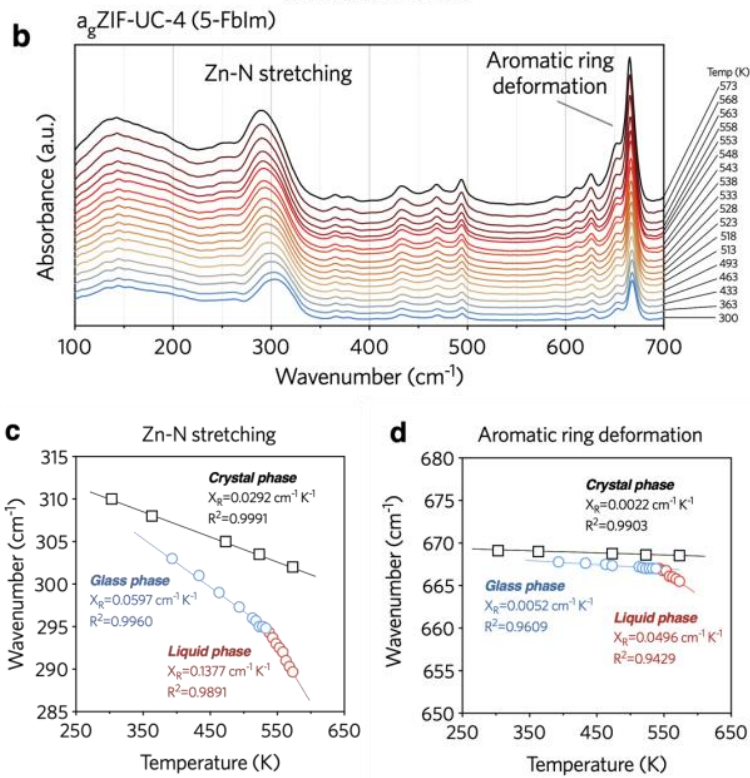

Figure 6. Synchrotron THz/Far-IR spectra during the heating of ZIFUC-4 (5-FbIm) and a ZIF-UC-4 (5-FbIm). Temperature-resolved in situ THz/Far-IR spectra for (a) ZIF-UC-4 (5-FbIm) and (b) agZIF-UC-4 (5$\mathrm{FbIm}$ ) up to $573 \mathrm{~K}$. (c) and (d) are the peak position shifts for the $\mathrm{Zn}-\mathrm{N}$ stretching and aromatic ring deformation modes respectively (see text for a detailed explanation of the graphs).

As expected, negligible changes are observed in the deformation-related behavior of the aromatic ring within crystalline ZIF-UC-4 (5-FbIm) upon heating (Figure 6d). The value of $X_{\mathrm{R}}$ is a magnitude smaller than that for the $\mathrm{Zn}-\mathrm{N}$ bond stretchingattributed to the rigidity of the aromatic ring. ${ }^{49}$ However, this same mode in a ZIF-UC-4 (5-FbIm) displays a substantial redshift when the temperature approaches $T_{\mathrm{g}}(c a .563 \mathrm{~K}$, Figure 6d). For example, while the $X_{\mathrm{R}}$ for $\mathrm{Zn}-\mathrm{N}$ of $\mathrm{a}_{\mathrm{g}} \mathrm{ZIF}-\mathrm{UC}-4$ (5FbIm) increases by 1.3 times above the $T_{\mathrm{g}}$, the $\mathrm{a}_{\mathrm{g}} \mathrm{ZIF}-\mathrm{UC}-4$ (5FbIm) $X_{\mathrm{R}}$ for aromatic ring deformation increases to nearly 10 times of the original value (0.0052 to $0.0496 \mathrm{~cm}^{-1} \mathrm{~K}^{-1}$, Figure 6d) upon heating above $T_{\mathrm{g}}$.

To further confirm the phenomenon, we conducted in situ THz/Far-IR heating tests for all halogenated ZIFs (ZIF-UC-2 (6-Cl-5-FbIm): Figure S56-58; ZIF-UC-3 (5-Cl-2-mbIm): Figure S59-61; ZIF-UC-5 (5-ClbIm): Figure S62-64), together with ZIF-62 (Figure S65-67), and observed similar behavior for all crystals and glasses. The $T_{\mathrm{g}}$ of $\mathrm{a}_{\mathrm{g}} \mathrm{ZIF}-\mathrm{UC}-3$ (5-Cl-2mbIm), $a_{\mathrm{g}}$ ZIF-UC-5 (5-ClbIm) and $\mathrm{a}_{\mathrm{g}} \mathrm{ZIF}-62$ are all above 573 $\mathrm{K}$, i.e. the maximum temperature of this experiment, and thus little variance in $X_{\mathrm{R}}$ values is noted. ${ }^{21}$ However, similar changes in $X_{\mathrm{R}}$ above the $T_{\mathrm{g}}$ of $c a .523 \mathrm{~K}$, are observed for $\mathrm{a}_{\mathrm{g}} \mathrm{ZIF}-\mathrm{UC}-2$ (6-Cl-5-FbIm). Interestingly, the $\mathrm{Zn}-\mathrm{N}$ stretching $X_{\mathrm{R}}$ for different ZIF crystals follows the order of ZIF-UC-3 (5-Cl-2-mbIm)

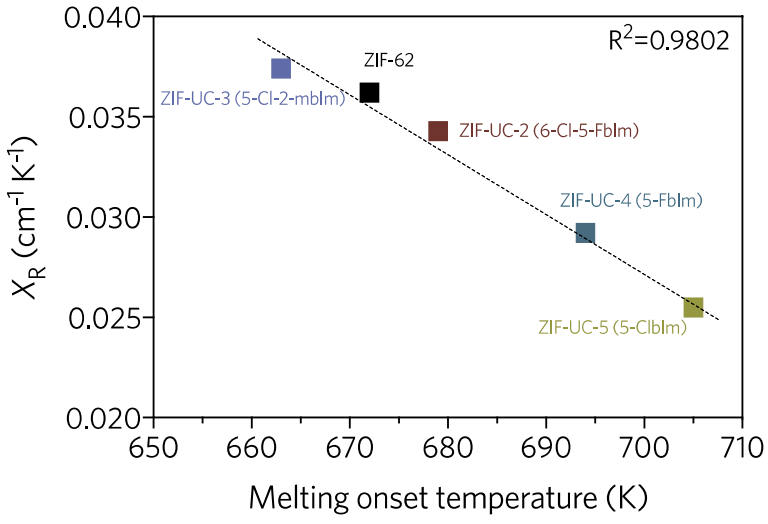

Figure 7. Correlation between the melting onset temperature and $X_{\mathrm{R}}$.

$\left(0.0374 \mathrm{~cm}^{-1} \mathrm{~K}^{-1}\right)>$ ZIF-62 $\left(0.0362 \mathrm{~cm}^{-1} \mathrm{~K}^{-1}\right)>$ ZIF-UC-2 $(6-$ Cl-5-FbIm) $\left(0.0343 \mathrm{~cm}^{-1} \mathrm{~K}^{-1}\right)>$ ZIF-UC-4 (5-FbIm) $(0.0292$ $\left.\mathrm{cm}^{-1} \mathrm{~K}^{-1}\right)>$ ZIF-UC-5 (5-ClbIm) $\left(0.0255 \mathrm{~cm}^{-1} \mathrm{~K}^{-1}\right)$, which shows excellent agreement with their melting onset temperatures (Figure 7, Table S9).

The decrease in melting temperature with greater values of $X_{\mathrm{R}}$ is consistent with the computationally calculated melting mechanism for ZIFs. For example, melting has been theorized to proceed via metal-linker bond breaking at a critical temperature, where the ratio of the thermally-induced vibrational amplitude of $\mathrm{N}$ atoms metal-linked atoms (i.e. $\mathrm{N}$ ) and the $\mathrm{M}-\mathrm{N}$ bond distance reach a critical point, i.e. Lindemann's law. ${ }^{9}$ Since $X_{\mathrm{R}}$ describes the increasing deformation of the $\mathrm{ZnN}_{4}$ tetrahedra, it must also be correlated to both bond distance and the thermal vibration of the ligand. We also observe the melting tendency has no clear correlation with the $\mathrm{Zn}-\mathrm{N}$ bond strength at room temperature (Figure S68).

\section{Porosity}

ZIF-UC-2 (6-Cl-5FbIm), ZIF-UC-3 (5-Cl-2-mbIm), ZIF-UC-4 (5-FbIm) and ZIF-UC-5 (5-ClbIm) all display a low $\mathrm{N}_{2}$ uptake at $77 \mathrm{~K}$ (Figure S69) with relatively low level of BET surface areas, in the range of $c a .7 .10-86.73 \mathrm{~m}^{2} / \mathrm{g} .{ }^{50}$ These values are consistent with the data reported in the literature, where the relatively dense structure of ZIF-62 blocks the entry and exit of $\mathrm{N}_{2}$ gas molecules into its inner framework structure. ${ }^{51}$ On the other hand, smaller gas molecules like $\mathrm{CO}_{2}$ can diffuse into the crystalline framework, and the absence of adsorption/desorption hysteresis indicated the rapid adsorptive/desorptive kinetics for these crystals (measured at $273 \mathrm{~K}$, Figure S70). Our earlier work demonstrates that a reduction in porosity, and thus gas adsorption capacity, is to be expected after vitrification of a crystalline ZIF. ${ }^{19}$ A substantial degree of microporosity can however, be preserved due to the presence of bulky bIm-based ligands, which prevents the total collapse of the porous interior upon liquid formation. ${ }^{11,17} \mathrm{CO}_{2}$ adsorption isotherms at $273 \mathrm{~K}$ for the melt-quenched glass samples confirm this is also the case here (Figure 8a): all melt-quenched ZIF glasses show reversible adsorption of $\mathrm{CO}_{2}$, suggesting the relatively rapid diffusion of guest molecules within these microporous structures.

The incorporation of fluorinated ligands can improve the $\mathrm{CO}_{2}$ uptake for both crystalline and glass materials. For example, despite ZIF-UC-4 (5-FbIm) and ZIF-UC-5 (5-ClbIm) exhibiting comparable quantities of bulky bIm-based ligands (Table 2), 

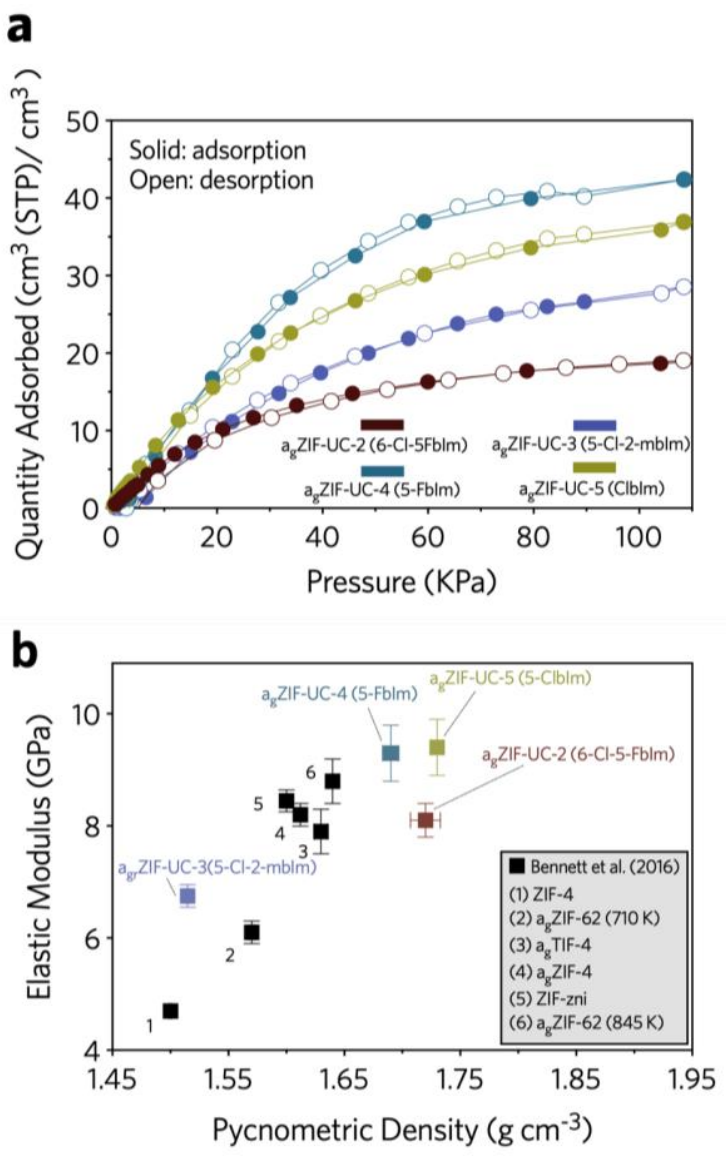

Figure 8 (a) $\mathrm{CO}_{2}$ gas adsorption/desorption isotherm for melt-quenched ZIF glasses. (b) Ashby-style plot of existing MOF glasses in this work, alongside the materials reported. ${ }^{14}$

ZIF-UC-4 (5-FbIm) exhibits a markedly higher $\mathrm{CO}_{2}$ uptake which is rationalized in terms of the stronger interaction between $\mathrm{CO}_{2}$ guests and framework $\mathrm{F}$ atoms in the narrow channels of the MOF. ${ }^{52}$ Similar behavior of other F-functionalized MOFs has been reported by other researchers. ${ }^{53-55}$ After melting, $\mathrm{a}_{\mathrm{g}} \mathrm{ZIF}-\mathrm{UC}-4$ (5-FbIm) displays a $\mathrm{CO}_{2}$ uptake of $42 \mathrm{~cm}^{3}$ (STP) $/ \mathrm{cm}^{3}$ at 1 bar, which is $c a .15 \%$ higher than $\mathrm{a}_{\mathrm{g}} \mathrm{ZIF}-\mathrm{UC}$ 5 (5-ClbIm) and ca. $30 \%$ higher than $\mathrm{a}_{\mathrm{g}} \mathrm{ZIF}-62 .{ }^{19}$

\section{Mechanical properties}

Nanoindentation has been previously applied to investigate the mechanical properties including Young's moduli $(E)$ and hardness of crystalline and amorphous MOFs. ${ }^{14,21}$ The average Young's modulus was recorded from load-displacement data (200 - $1000 \mathrm{~nm}$ ) on polished glass samples (Figure S71-74). Both $\mathrm{a}_{\mathrm{g}}$ ZIF-UC-4 (5-FbIm) and a ZIF-UC-5 (5-ClbIm) show comparable values of $E \approx 9.4$ and $9.3 \mathrm{GPa}$, respectively, placing them roughly at the upper bound of the existing ZIF glasses (Figure 8b and Figure S75). The mechanical properties of MOF materials do not always follow density-stiffness rules, but are determined more by the primary (metal-organic coordination structure) and the secondary network, the nonbonded interactions, which provide extra support for the structural weak points. ${ }^{56}$ Consistent with these reports, we postulate that the presence of halogenated moieties on the bIm-derived ligands can introduce more effective secondary network structures via nonbonded interactions, or indeed by the $\mathrm{Zn}-\mathrm{F}$ bonds, which raise $E$ in these cases above that found for a $\mathrm{a}$ IF-62 $(E \approx 6.1$ $8.8 \mathrm{GPa}$, Figure $8 \mathbf{b}$ ). Attempts have also been made to prepare bulk halogenated glass samples, by first pelletizing samples of $\mathrm{a}_{\mathrm{g}} \mathrm{ZIF}-\mathrm{UC}-3$ (5-Cl-2-mbIm), before annealing above the glass $T_{\mathrm{g}}{ }^{57}$ The resultant bulk glass (termed as agr ZIF-UC-3 (5-Cl-2mbIm)) has a dark brown, opaque appearance, with a diameter of $13 \mathrm{~mm}$ (Figure S76), and Young's modulus of $6.66 \pm 0.14$ GPa.

\section{Conclusion}

Four new crystalline ZIFs, ZIF-UC-2 (6-Cl-5-FbIm), ZIF-UC3 (5-Cl-2-mbIm), ZIF-UC-4 (5-FbIm) and ZIF-UC-5 (5ClbIm) have been reported and have all been shown to undergo melting. The melting of ZIFs has previously been reported to be affected by the crystal structure of the precursor, the stoichiometric ratio of different ligands, and the type of metal node. ${ }^{16,18}$ The array of experimental techniques provided here show that the presence of electron withdrawing moieties on the benzimidazolate ligand may weaken the $\mathrm{Zn}-\mathrm{N}$ bond, and also lead to a small reduction in the melting temperature of the ZIF crystal. The results also show that the presence of bulkier ligands results in a lower free activation energy through dispersive interaction-based stabilization of dissociated ligands in the liquid phase. These findings are encapsulated by in situ THz/Far-IR studies, which reveal the connection between $\mathrm{Zn}$ $\mathrm{N}$ bond motion and melting behavior. Specifically, they provide evidence of a correlation between the ZIF melting temperature and the propensity of thermal-induced $\mathrm{Zn}-\mathrm{N}$ polyhedral deformation, which provides experimental evidence of melting mechanism being underpinned by the thermally-induced vibrational amplitude of the $\mathrm{N}$ atoms reaching a critical point, which leads to the breaking of the $\mathrm{M}-\mathrm{N}$ bond.

In addition, solid-state NMR results provide specific evidence for the formation of $\mathrm{Zn}-\mathrm{F}$ bonding in the glass phase, implying a reduction in overall network connectivity. The extent of this rearrangement process is dependent upon treatment temperature, though the fate of the proportion of fluorobenzimidazolate ligands from which $\mathrm{F}$ detaches is beyond the scope of this work. The presence of a fluorinated moiety within the glass of ZIF-UC-4 (5-FbIm) also notably improves gas uptake for $\mathrm{CO}_{2}$, compared with ZIF-62 and ZIF-UC-5 (5-ClbIm) containing chlorinated benzimidazole ligands.

The results help explain the glass forming ability of ZIF materials, which were analysed using their respective $T_{\mathrm{g}} / T_{\mathrm{m}}$ ratios (Table 2). This ratio for conventional metallic, covalent and ionic melt quenched glasses follows the empirical Kauzmann " $2 / 3$ Law", 34 and has been used previously to suggest the resistance to recrystallization of the supercooled liquid state. ${ }^{18}$ The highest GFA (0.92) for the samples studied here is observed for ZIF-UC-3 (5-Cl-2-mbIm). This is ascribed to the presence of the sterically bulky 5-Cl-2-mbIm ligand, which suppresess the extent of diffusion in the liquid phase. This is higher than the reported GFA for ZIF-62 (0.88). At the same time, slightly lower GFAs for the ZIF-UC-2 (0.77) and ZIF-UC-4 (0.81) are attributed to the formation of $\mathrm{Zn}-\mathrm{F}$ bonds, which breaks the continuity of the random network and improves the diffusivity of the ligands in ZIF liquid, thus lowering $T_{\mathrm{g}}$. The GFAs for the halogenated ZIFs are still higher than the conventional ionic, metallic and covalent glasses. 
Importantly, together with recent progress on lowering the melting temperature of ZIFs through (i) adjustment of organic linker ratio, (ii) inclusion of multiple organic linkers and (iii) cobalt, these results may be used to further lower the melting temperature of ZIFs. Such research is essential if industrially viable working temperatures are to be achieved and larger scale studies on the applications of such glasses are to be performed.

\section{ASSOCIATED CONTENT}

\section{Supporting Information}

The Supporting Information is available free of charge on the ACS Publications website.

Experimental and characterization procedures. Data on crystal structure, PXRD and Pawley refinement, liquid-state NMR, solid-state NMR, DFT calculation for charge density distribution, SEM image, FTIR, X-ray total scattering, pair distribution function, synchrotron THz/FarIR spectra, gas sorption, nanoindentation and density.

Crystallographic data for ZIF-UC-2 (ClFbIm), ZIF-UC-3 (ClmbIm), ZIF-UC-4 (FbIm) and ZIF-UC-5 (ClbIm).

\section{AUTHOR INFORMATION}

\section{Corresponding Author}

*tdb35@cam.ac.uk

\section{ACKNOWLEDGMENT}

T.D.B. thanks the Royal Society for a University Research Fellowship (UF150021) and a research grant (RSGIR1\180395). J.H. and T.D.B also thank EPSRC (EP/R015481/1). J.H. thanks the Australian Research Council for a DECRA Fellowship (DE190100803). V. C. acknowledges financial support (DP180103874). S. L. acknowledges the China Scholarship Council (CSC). A. F. S. acknowledges the EPSRC for a PhD studentship under the industrial CASE scheme along with Johnson Matthey PLC (JM11106). A. M. B. acknowledges the Royal Society for funding (RGFIEA 180092) as well as the Cambridge Trust for a Vice Chancellor's Award (304253100). Z.D. thanks the Cambridge Trust and the China Scholarship Council. The calculations were performed at the U.K. National Supercomputing Service, ARCHER. Access was obtained via the UKCP consortium and funded by EPSRC under Grant No. EP/P022596/1. A.K. and G.M. acknowledge the financial support from the Slovenian Research Agency (research core funding No. P1-0021 and research project Z1-9171). We thank U. Javornik for help with the liquid-state ${ }^{19} \mathrm{~F}$ NMR measurements. Generous computational resources are provided (to BC) by RIKEN Information Systems Division (project Q19266). The authors acknowledge the facilities, and the scientific and technical assistance, of the Australian Microscopy \& Microanalysis Research Facility at the Centre for Microscopy and Microanalysis, The University of Queensland. Part of this research was undertaken on the THz/Far-IR beamline at the Australian Synchrotron, part of ANSTO (M14790 and EU15604). We acknowledge the provision of synchrotron access to Beamline I15-1 (EE20038-1 and EE20038-2) at the Diamond Light Source.

\section{REFERENCES}

(1) Stassen, I.; Burtch, N.; Talin, A.; Falcaro, P.; Allendorf, M.; Ameloot, R. An updated roadmap for the integration of metal-organic frameworks with electronic devices and chemical sensors. Chem. Soc. Rev. 2017, $46(11), 3185-3241$

(2) Furukawa, H.; Cordova, K. E.; O'Keeffe, M.; Yaghi, O. M. The chemistry and applications of metal-organic frameworks. Science 2013, 341 (6149), 1230444.
(3) Bennett, T. D.; Cheetham, A. K.; Fuchs, A. H.; Coudert, F.-X. Interplay between defects, disorder and flexibility in metal-organic frameworks. Nat. Chem. 2016, 9 (1), 11-16.

(4) Cai, G.; Jiang, H.-L. A modulator-induced defect-formation strategy to hierarchically porous metal-organic frameworks with high stability. Angew. Chem. 2017, 129 (2), 578-582.

(5) Cliffe, M. J.; Castillo-Martínez, E.; Wu, Y.; Lee, J.; Forse, A. C.; Firth, F. C. N.; Moghadam, P. Z.; Fairen-Jimenez, D.; Gaultois, M. W.; Hill, J. A.; Magdysyuk, O. V.; Slater, B.; Goodwin, A. L.; Grey, C. P. Metalorganic nanosheets formed via defect-mediated transformation of a hafnium metal-organic framework. J. Am. Chem. Soc. 2017, 139 (15), 5397-5404.

(6) Chen, W.; Horike, S.; Umeyama, D.; Ogiwara, N.; Itakura, T.; Tassel, C.; Goto, Y.; Kageyama, H.; Kitagawa, S. Glass formation of a coordination polymer crystal for enhanced proton conductivity and material flexibility. Angew. Chem. Int. Ed. 2016, 55 (17), 5195-5200.

(7) Krause, S.; Bon, V.; Senkovska, I.; Stoeck, U.; Wallacher, D.; Többens, D. M.; Zander, S.; Pillai, R. S.; Maurin, G.; Coudert, F.-X.;Kaskel, S. A pressure-amplifying framework material with negative gas adsorption transitions. Nature 2016, 532 (7599), 348-352.

(8) Dissegna, S.; Epp, K.; Heinz, W. R.; Kieslich, G.; Fischer, R. A. Defective metal-organic frameworks. Adv. Mater. 2018, 30 (37), 1704501. (9) Gaillac, R.; Pullumbi, P.; Beyer, K. A.; Chapman, K. W.; Keen, D. A.; Bennett, T. D.; Coudert, F.-X. Liquid metal-organic frameworks. Nat. Mater. 2017, 16 (11), 1149-1154.

(10) Zhao, Y.; Lee, S.-Y.; Becknell, N.; Yaghi, O. M.; Angell, C. A. Nanoporous transparent MOF glasses with accessible internal surface. J. Am. Chem. Soc. 2016, 138 (34), 10818-10821.

(11) Frentzel-Beyme, L.; Kloß, M.; Pallach, R.; Salamon, S.; Moldenhauer, H.; Landers, J.; Wende, H.; Debus, J.; Henke, S. Porous purple glass - a cobalt imidazolate glass with accessible porosity from a meltable cobalt imidazolate framework. J. Mater. Chem. A 2019, 7 (3), 985-990.

(12) Bennett, T. D.; Todorova, T. K.; Baxter, E. F.; Reid, D. G.; Gervais, C.; Bueken, B.; Van de Voorde, B.; De Vos, D.; Keen, D. A.; Mellot-Draznieks, C. Connecting defects and amorphization in UiO-66 and MIL-140 metal-organic frameworks: a combined experimental and computational study. Phys Chem Chem Phys 2016, 18 (3), 2192-2201.

(13) Bennett, T. D.; Horike, S. Liquid, Glass and amorphous solid states of coordination polymers and metal-organic frameworks. Nat. Rev. Mater. 2018. 3, 431-440.

(14) Bennett, T. D.; Yue, Y.; Li, P.; Qiao, A.; Tao, H.; Greaves, N. G.; Richards, T.; Lampronti, G. I.; Redfern, S. A. T.; Blanc, F.; et al. Meltquenched glasses of metal-organic frameworks. J. Am. Chem. Soc. 2016, 138 (10), 3484-3492.

(15) Bennett, T. D.; Tan, J.-C.; Yue, Y.; Baxter, E.; Ducati, C.; Terrill, N. J.; Yeung, H. H.-M.; Zhou, Z.; Chen, W.; Henke, S.; Cheetham, A. K; Greaves G. N. Hybrid glasses from strong and fragile metal-organic framework liquids. Nat. Commun. 2015, 6, 8079.

(16) Frentzel-Beyme, L.; Kloss, M.; Kolodzeiski, P.; Pallach, R.; Henke, $\mathrm{S}$. Meltable mixed-linker zeolitic imidazolate frameworks and their microporous glasses - from melting point engineering to selective hydrocarbon sorption. J. Am. Chem. Soc. 2019, 141 (3) 12362-12371.

(17) Zhou, C.; Longley, L.; Krajnc, A.; Smales, G. J.; Qiao, A.; Erucar, I.; Doherty, C. M.; Thornton, A. W.; Hill, A. J.; Ashling, C. W.;Qazvini, Q. T.; Lee, S. J.; Chater, P. A., Terrill, N. J.; Smith, A. J.; Yue, Y.; Mali, G.; Keen, D. A.; Telfer, S. G.; Bennett, T. D. Metal-organic framework glasses with permanent accessible porosity. Nat. Commun. 2018, 9 (1), 5042.

(18) Qiao, A.; Bennett, T. D.; Tao, H.; Krajnc, A.; Mali, G.; Doherty, C. M.; Thornton, A. W.; Mauro, J. C.; Greaves, G. N.; Yue, Y. A metal-organic framework with ultrahigh glass-forming ability. Sci. $A d v$. 2018, 4 (3), eaao6827.

(19) Widmer, R. N.; Lampronti, G. I.; Anzellini, S.; Gaillac, R.; Farsang, S.; Zhou, C.; Belenguer, A. M.; Wilson, C. W.; Palmer, H.; Kleppe, A. K.; Wharmby, M. T.; Yu, X.; Cohen, S. M.; Telfer, S. G., Redfern, S. A. T.; Coudert, X.-F; Macleod, S. G.; Bennett, T. D. Pressure promoted low-temperature melting of metal-organic frameworks. Nat. Mater. 2019, 18 (4), 370-376.

(20) Tuffnell, J. M.; Ashling, C. W.; Hou, J.; Li, S.; Longley, L.; Ríos Gómez, M. L.; Bennett, T. D. Novel metal-organic framework materials: blends, liquids, glasses and crystal-glass composites. Chem. Commun. 2019, 55 (60), 8705-8715.

(21) Hou, J.; Ashling, C. W.; Collins, S. M.; Krajnc, A.; Zhou, C.; Longley, L.; Johnstone, D. N.; Chater, P. A.; Li, S.; Coulet, M.-V.; Llewellyn, P. L.; Coudert, F.-X.; Keen, D. A.; Midgley, P. A., Mali, G.; Chen, V.; 
Bennett, T. D. Metal-organic framework crystal-glass composites. Nat. Commun. 2019, 10 (1) 2580.

(22) Ashling, C. W.; Johnstone, D. N.; Widmer, R. N.; Hou, J.; Collins, S. M.; Sapnik, A. F.; Bumstead, A. M.; Midgley, P. A.; Chater, P. A.; Keen, D. A.; Bennett, T. D. Synthesis and properties of a compositional series of MIL-53(Al) metal-organic framework crystal-glass composites. J. Am. Chem. Soc. 2019, 141 (39), 15641-15648.

(23) Moghadam, P. Z.; Li, A.; Wiggin, S. B.; Tao, A.; Maloney, A. G. P.; Wood, P. A.; Ward, S. C.; Fairen-Jimenez, D. Development of a cambridge structural database subset: a collection of metal-organic frameworks for past, present, and future. Chem. Mater. 2017, 29 (7), 2618-2625.

(24) Nagarkar, S. S.; Kurasho, H.; Duong, N. T.; Nishiyama, Y.; Kitagawa, S.; Horike, S. Crystal melting and glass formation in copper thiocyanate based coordination polymers. Chem. Commun. 2019, 55 (38), 54555458 .

(25) Widmer, R. N.; Lampronti, G. I.; Chibani, S.; Wilson, C. W.; Anzellini, S.; Farsang, S.; Kleppe, A. K.; Casati, N. P. M.; MacLeod, S. G.; Redfern, S. A. T.; Coudert, F.-X,; Bennett, T. D. Rich polymorphism of a metal-organic framework in pressure-temperature space. J. Am. Chem. Soc. 2019, 141 (23), 9330-9337.

(26) Gaillac, R.; Pullumbi, P.; Coudert, F.-X. Melting of zeolitic imidazolate frameworks with different topologies: insight from first-principles molecular dynamics. J. Phys. Chem. C 2018, 122 (12), 6730-6736.

(27) Chaplais, G.; Fraux, G.; Paillaud, J.-L.; Marichal, C.; Nouali, H.; Fuchs, A. H.; Coudert, F.-X.; Patarin, J. Impacts of the imidazolate linker substitution ( $\mathrm{ch}_{3}, \mathrm{cl}$, or br) on the structural and adsorptive properties of ZIF-8. J. Phys. Chem. C 2018, 122 (47), 26945-26955.

(28) Namsani, S.; Yazaydin, A. O. Electric field induced rotation of halogenated organic linkers in isoreticular metal-organic frameworks for nanofluidic applications. Mol. Syst. Des. Eng. 2018, 3 (6), 951-958.

(29) Peralta, D.; Chaplais, G.; Simon-Masseron, A.; Barthelet, K.; Pirngruber, G. D. Synthesis and adsorption properties of zif-76 isomorphs. Microporous Mesoporous Mater. 2012, 153, 1-7.

(30) Banerjee, R.; Phan, A.; Wang, B.; Knobler, C.; Furukawa, H.; O'Keeffe, M.; Yaghi, O. M. High-throughput synthesis of zeolitic imidazolate frameworks and application to $\mathrm{CO}_{2}$ Capture. Science 2008, 319 (5865), 939-943.

(31) Yang, J.; Zhang, Y.-B.; Liu, Q.; Trickett, C. A.; Gutiérrez-Puebla, E.; Monge, M. Á.; Cong, H.; Aldossary, A.; Deng, H.; Yaghi, O. M. Principles of designing extra-large pore openings and cages in zeolitic imidazolate frameworks. J. Am. Chem. Soc. 2017, 139 (18), 6448-6455.

(32) Ríos Gómez, M. L.; Lampronti, G. I.; Yang, Y.; Mauro, J. C.; Bennett, T. D. Relating structural disorder and melting in complex mixed ligand zeolitic imidazolate framework glasses. Dalton Trans. 2020 in press. DOI: $10.1039 / \mathrm{c} 9 \mathrm{dt} 03559 \mathrm{a}$

(33) Longley, L.; Collins, S. M.; Zhou, C.; Smales, G. J.; Norman, S. E.; Brownbill, N. J.; Ashling, C. W.; Chater, P. A.; Tovey, R.; Schönlieb, C.B.; Headen, T. F.; Terrill, N. J.; Yue, Y.; Smith, A. J.; Blanc, F.; Keen, D. A.; Midgley, P. A.; Bennett, T. D. Liquid Phase blending of metal-organic frameworks. Nat. Commun. 2018, 9 (1), 2135.

(34) Ito, K.; Moynihan, C. T.; Angell, C. A. Thermodynamic determination of fragility in liquids and a fragile-to-strong liquid transition in water. Nature 1999, 398 (6727), 492-495.

(35) Donth, E.-J. The Glass Transition; Zunger, A., Osgood, R. M., Hull, R., Sakaki, H., Series Eds.; Springer Series in MATERIALS SCIENCE; Springer Berlin Heidelberg: Berlin, Heidelberg, 2001; Vol. 48.

(36) Samanta, A.; Tuckerman, M. E.; Yu, T.-Q.; E, W. Microscopic mechanisms of equilibrium melting of a solid. Science 2014, 346 (6210), 729-732.

(37) Farrow, C. L.; Juhas, P.; Liu, J. W.; Bryndin, D.; Božin, E. S.; Bloch, J.; Proffen, T.; Billinge, S. J. L. PDFfit2 and PDFgui: computer programs for studying nanostructure in crystals. J. Phys. Condens. Matter 2007, 19 (33), 335219.

(38) Cai, S.-H.; Chen, Z.; Chen, Z.-W.; Wan, H.-L. ${ }^{19}$ F NMR chemical shielding for metal fluorides $\mathrm{MF}_{2}(\mathrm{M}=\mathrm{Zn}, \mathrm{Cd}, \mathrm{Pb}), \mathrm{MF}_{3}(\mathrm{M}=\mathrm{Al}, \mathrm{Ga}, \mathrm{In})$ and $\mathrm{SnF}_{4}$. Chem. Phys. Lett. 2002, 362 (1-2), 13-18.

(39) Cullis, C. F.; Priday, K. The thermal decomposition of aromatic compounds - I. Chlorobenzene. Proc. R. Soc. Lond. Ser. Math. Phys. Sci. 1954, 224 (1158), 308-321.
(40) Campbell, M. G.; Ritter, T. Modern carbon-fluorine bond forming reactions for aryl fluoride synthesis. Chem. Rev. 2015, 115 (2), 612-633.

(41) Xie, C.; Zhang, Y. A New tandem reaction of benzyne: one-pot synthesis of aryl amines containing anthracene. Org. Lett. 2007, 9 (5), 781784 .

(42) Yoshida, H.; Sugiura, S.; Kunai, A. Facile synthesis of $n$-alkyl- $n$ -arylimidazolium salts via addition of imidazoles to arynes. Org. Lett. 2002, 4 (16), 2767-2769.

(43) Baxter, J. B.; Guglietta, G. W. Terahertz spectroscopy. Anal. Chem. 2011, 83 (12), 4342-4368.

(44) Ryder, M. R.; Civalleri, B.; Bennett, T. D.; Henke, S.; Rudić, S.; Cinque, G.; Fernandez-Alonso, F.; Tan, J.-C. Identifying the role of terahertz vibrations in metal-organic frameworks: from gate-opening phenomenon to shear-driven structural destabilization. Phys. Rev. Lett. 2014, $113(21)$.

(45) Yang, S.; Sun, J.; Ramirez-Cuesta, A. J.; Callear, S. K.; David, W. I. F.; Anderson, D. P.; Newby, R.; Blake, A. J.; Parker, J. E.; Tang, C. C.; et al. Selectivity and direct visualization of carbon dioxide and sulfur dioxide in a decorated porous host. Nat. Chem. 2012, 4 (11), 887-894.

(46) Giordano, J.; Benoit, C. Infrared spectra of iron, zinc and magnesium fluorides: i. analysis of results. J. Phys. C Solid State Phys. 1988, 21 (14), 2749-2770.

(47) Viña, L.; Logothetidis, S.; Cardona, M. Temperature dependence of the dielectric function of germanium. Phys. Rev. B 1984, 30 (4), 1979-1991. (48) Shen, Y. C.; Upadhya, P. C.; Linfield, E. H.; Davies, A. G. Temperature-dependent low-frequency vibrational spectra of purine and adenine. Appl. Phys. Lett. 2003, 82 (14), 2350-2352.

(49) Ryder, M. R.; Bennett, T. D.; Kelley, C. S.; Frogley, M. D.; Cinque, G.; Tan, J.-C. Tracking thermal-induced amorphization of a zeolitic imidazolate framework via synchrotron in situ far-infrared spectroscopy. Chem. Commun. 2017, 53 (52), 7041-7044.

(50) Walton, K. S.; Snurr, R. Q. Applicability of the BET method for determining surface areas of microporous metal-organic frameworks. $J$. Am. Chem. Soc. 2007, 129 (27), 8552-8556.

(51) Longley, L.; Collins, S. M.; Li, S.; Smales, G. J.; Erucar, I.; Qiao, A.; Hou, J.; Doherty, C. M.; Thornton, A. W.; Hill, A. J.; Yu, X.; Terrill, N. J.; Smith, A. J.; Cohen, S. M.; Midgley, P. A.; Keen, D. A.; Telfer, S. G.; Bennett, T. D. Flux melting of metal-organic frameworks. Chem. Sci. 2019, 10 (12), 3592-3601.

(52) Nugent, P.; Belmabkhout, Y.; Burd, S. D.; Cairns, A. J.; Luebke, R.; Forrest, K.; Pham, T.; Ma, S.; Space, B.; Wojtas, L.; et al. Porous Materials with Optimal Adsorption Thermodynamics and Kinetics for $\mathrm{CO} 2$ Separation. Nature 2013, 495 (7439), 80-84. https://doi.org/10.1038/nature11893.

(53) Bhatt, P. M.; Belmabkhout, Y.; Cadiau, A.; Adil, K.; Shekhah, O.; Shkurenko, A.; Barbour, L. J.; Eddaoudi, M. A fine-tuned fluorinated MOF addresses the needs for trace $\mathrm{CO}_{2}$ removal and air capture using physisorption. J. Am. Chem. Soc. 2016, 138 (29), 9301-9307.

(54) Cadiau, A.; Belmabkhout, Y.; Adil, K.; Bhatt, P. M.; Pillai, R. S.; Shkurenko, A.; Martineau-Corcos, C.; Maurin, G.; Eddaoudi, M. Hydrolytically stable fluorinated metal-organic frameworks for energy-efficient dehydration. Science 2017, 356 (6339), 731-735.

(55) Liu, G.; Cadiau, A.; Liu, Y.; Adil, K.; Chernikova, V.; Carja, I.-D.; Belmabkhout, Y.; Karunakaran, M.; Shekhah, O.; Zhang, C.; Itta, A. K.; Yi, S.; Eddaoudi, M.; Joros, W. J. Enabling fluorinated MOF-based membranes for simultaneous removal of $\mathrm{H}_{2} \mathrm{~S}$ and $\mathrm{CO}_{2}$ from natural gas. Angew. Chem. Int. Ed. 2018, 57 (45), 14811-14816.

(56) Moosavi, S. M.; Boyd, P. G.; Sarkisov, L.; Smit, B. Improving the mechanical stability of metal-organic frameworks using chemical caryatids. ACS Cent. Sci. 2018, 4 (7), 832-839.

(57) Li, S.; Limbach, R.; Longley, L.; Shirzadi, A. A.; Walmsley, J. C.; Johnstone, D. N.; Midgley, P. A.; Wondraczek, L.; Bennett, T. D. Mechanical properties and processing techniques of bulk metal-organic framework glasses. J. Am. Chem. Soc. 2019, 141 (2), 1027-1034. 


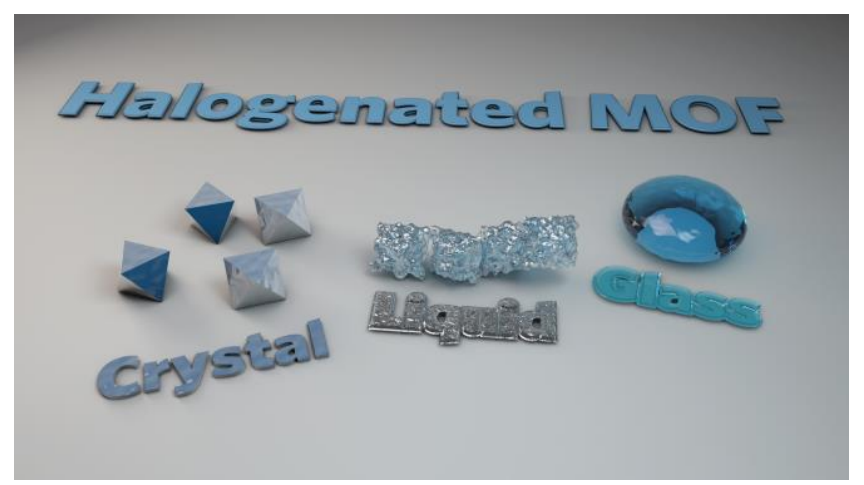

